\section{Compliance with ethical standards}

Conflict of interest The authors declare that they have no conflict of interest.

\section{References}

1. Haberland C, Perou M. Encephalocraniocutaneous lipomatosis. A new example of ectomesodermal dysgenesis. Arch Neurol. 1970;22:144-55.
2. Bavle A, Shah R, Gross N, et al. Encephalocraniocutaneous Lipomatosis. J Pediatr Hematol Oncol. 2018. Epub ahead of print.

3. Muñoz-Montufar JP, Rayo-Mares JD, Reyes-Cuayahuitl A. et al. Lipomatosis encefalocraneocutánea: reporte de caso. Gac Med Mex. 2017;153:915-8.

4. Almer Zina, Vishnevskia-Dai Victoria, Zadok David. et al. Encephalocraniocutaneous lipomatosis: case report and review of the literature. Cornea. 2003;22:389-390.

5. Moog U. Encephalocraniocutaneous lipomatosis. J Med Genet. 2009;46:721-9.

\title{
Comment on: Proposal for a new classification for ocular surface squamous neoplasia
}

\author{
Lindsay A. McGrath ${ }^{1}$. Sachin M. Salvi $\mathbb{B}^{1}$ \\ Received: 4 September 2018 / Accepted: 4 October 2018 / Published online: 18 October 2018 \\ (c) The Royal College of Ophthalmologists 2018
}

We read with interest Meel and Dhiman's recent proposal for a new classification for ocular surface squamous neoplasia (OSSN) [1]. The authors offer a modified criteria for conjunctival neoplasia that takes into account invasion (on ultrasound biomicrosopy (UBM)) and provides a rough guide for treatment. They suggest that OSSN of Grade III (with intraocular involvement present) should be managed with enucleation.

The potential of advanced ocular surface squamous lesions to invade through the sclera or cornea is well recognised with enucleation being the traditional management [2]. However, many studies over the past decade have shown success with globe-sparing therapy for these advanced lesions-and it is certainly our experience that invasive squamous lesions can be managed in this way [3]. Shields et al. showed that plaque brachytherapy is a safe and reliable alternative to globe removal for eyes with conjunctival squamous cell carcinoma (SCC) showing scleral invasion and/or intraocular involvement [2]. Further, Graue et al. demonstrated local tumour control in $75 \%$ of

Lindsay A. McGrath

lindsay.mcg@gmail.com

1 Sheffield Ocular Oncology Service, Royal Hallamshire Hospital, Sheffield S10 2JF, UK recalcitrant conjunctival SCCs treated with electron beam radiotherapy [4].

The relevance of the American Joint Committee on Cancer (AJCC) staging of conjunctival SCC in guiding initial management was challenged in a recent work by Belleverie et al. [5]. They also suggest reclassification of the T3 category (diffuse vs deep invading) to better guide initial treatment. However, similar to previous reports, these authors also advocate the use of surface brachytherapy for scleral invasion of SCC [5].

The AJCC publications are recognised as authoritative guides for cancer staging and communicating information about cancer. Evidence-based staging is important to guide therapy and define prognosis, and the AJCC aims to help doctors design a treatment plan for individual patients. Meel and Dhiman's proposal include treatment in their modified staging system, and, although these management options are perhaps not available in their centre, we feel it would be useful to include staged options of therapy for advanced lesions as alternative to enucleation [1]. There appears to be an error in the classification table, listing Grade II lesions incorrectly as having no invasion into ocular coats on imaging, which contradicts the imaging findings and manuscript definitions of this grade.

We support the current classification system published by the AJCC, but agree with recent studies suggesting reclassification of the T3 category [5]. 


\section{Compliance with ethical standards}

Conflict of interest The authors declare that they have no conflict of interest.

\section{References}

1. Meel R, Dhiman R. Proposal for a new classification for ocular surface squamous neoplasia. Eye. 2018;32:1284-5.

2. Shields CL, Chien JL, Surakiatchanukul T, Sioufi K, Lally SE, Shields JA. Conjunctival tTumors: review of clinica features, risks, biomarkers, and outcomes - the 2017 J.Donald M. Gass LLecture. Asia Pac J Ophthalmol. 2017;6:109-20.

3. El-Assal KS, Salvi SM, Rundle PA, Mudhar HS, Rennie IG. Treatment of invasive ocular surface squamous neoplasia with proton beam therapy. Eye. 2013 Oct;27(10):1223.

4. Graue GF, Tena LB, Finger PT. elElectron beam radiation for conjunctival squamous carcinoma. Ophthal Plas Reconstr Surg. 2011;27:277-81.

5. Bellerive C, Berry JL, Polski A, Singh AD. Conjunctival squamous neoplasia: staging and initial treatment. Cornea. 2018. https://doi. org/10.1097/ICO.0000000000001651.

\title{
Response to 'Comment on: Proposal for a new classification for ocular surface squamous neoplasia'
}

\author{
Rachna Meel ${ }^{1} \cdot$ Rebika Dhiman $^{1}$ \\ Published online: 19 October 2018 \\ (c) The Royal College of Ophthalmologists 2018
}

We thank McGrath and Salvi [1] for their valuable comments and suggestions.

There are no published guidelines for treatment of ocular surface squamous neoplasia (OSSN). Also, clinical spectrum of OSSN varies significantly between different continents like Africa and North America or Australia [2]. Clinical presentation is significantly delayed in resource-constrained countries, and hence use of conservative management options like plaque brachytherapy are not only limited by availability but also by feasibility.

The conventional method of treatment for OSSN is wide local surgical excision using a 'no touch technique' and cryotherapy of conjunctival edges. Topical treatment with chemotherapeutic agents and interferons has become popular in the past 1-2 decades due to the inherent benefits of topical treatment-treatment of a complete ocular surface, thus reducing the chances of microscopic residual disease, lesser side effects of treatment as compared to surgical excision, especially in giant or diffuse tumors and the relative ease of

Rachna Meel

dr.rachnameel@gmail.com

1 Oculoplasty and Ocular Oncology Services, Dr R P Centre for Ophthalmic Sciences, All India Institute of Medical Sciences, New Delhi 110029, India administering treatment. Traditionally, enucleation is done for tumors with intraocular extension and exenteration for OSSN with orbital extension.

We agree with the authors that, technology-dependent treatment modalities, like plaque brachytherapy and proton beam therapy may not be available in resource-constrained countries. There are adequate reports in literature to show that brachytherapy effectively controls OSSN invading into the ocular coats and hence may be used as an adjuvant treatment in cases with incomplete tumor resection (Table 1) (the same has been added in the treatment options for grade II tumor in the revised table) [3]. However, its use in OSSN with overt (obvious on imaging (UBM) or clinically) intraocular extension is still being explored and needs to be evaluated in further studies [4]. We, at our center are now using adjuvant plaque brachytherapy in cases of invasive SCC, where there is microscopic residual disease in the ocular coats after surgery.

The proposed classification attempts to address the concerns with AJCC classification, as reported by previous studies and intends to give a rough guideline for treatment based on most commonly available treatment modalities [4]. While enucleation and exenteration remain the most common method of treatment for tumor with ocular and orbital extension, respectively, the treatment scenario for OSSN with 